\title{
Making sense out of syngamy at the onset of mammalian development
}

\author{
David F. Albertini ${ }^{1}$ \\ Published online: 2 August 2018 \\ (C) Springer Science+Business Media, LLC, part of Springer Nature 2018
}

Breaking cardinal rules and fundamental tenets of early development in mammals seems to be happening with some regularity these days. The reasons are obvious, for those willing to accept the role that technology brings to an evolving perspective centered on what we thought had been etched in stone. The matter at hand is the process of syngamy. The technology at hand is four-dimensional imaging.

This month, our lead paper takes an in-depth look at the fate of single pronucleate human zygotes (Assessment of developmental potential of human single pronucleated zygotes derived from conventional in vitro fertilization https://doi.org/ $10.1007 / \mathrm{s} 10815-018-1241$ ). If your mantra is "seeing is believing," then careful inspection of the supplement movies will uncover subcellular details that far exceed the capabilities of time-lapse imaging as we know it today in the world of ARTs. And over and above the biological and clinical implications of their work, the high-resolution approaches being taken by Mio and others like the EMBO Heidelberg group (see below)-reaching conclusions founded on lowresolution data sets - raise serious questions regarding the practice of every day ARTs and our understanding of basic processes like syngamy.

Syngamy has become an acceptable sentinel for the beginning of life. Nearly a century ago, a generation of cell and developmental biologists laid down the groundwork for the biology of fertilization in EB Wilson's treatise of 1925 [1]. Compiled, congealed, and constitutional in nature, tales of syngamy based on the tools of cytology recognized the importance of that special moment in the life history of all sexually reproducing metazoans. That nuptial encounter between the genomes of mom and dad, with the subsequent and equivalent segregation of maternal and paternal chromosomes on a mitotic spindle, has become a building block for our understanding of how embryo development is launched on the

David F. Albertini

eicjarg@gmail.com

1 Center for Human Reproduction, New York, NY, USA pathway to implantation and beyond. That the sperm brings more than a genome to this BYOB (bring your own bottle) affair has long been accepted in the case of humans, emphasizing the role of the paternally inherited centrosome in construction of that first bipolar mitotic spindle [2].

Fast forward 75 years to the prescient work of Mayer and colleagues, where in an elegant series of experiments on mouse embryos, the stage of development when mom and dad consummate their genome merger is called into question (a probable reason why this work has been virtually buried in the literature) $[3,4]$. These papers suggested that maternal and paternal chromosomes retained a spatially exclusive location within blastomere nuclei through the first three cell cycles, after which both genomes became spatially integrated into one.

Since these studies were published, the development and application of live cell imaging techniques has blossomed in many biomedical research disciplines. And among those pushing the limits of conventional and novel microscopic techniques in human ARTs, and willing to overcome some of the methodical obstacles associated with monitoring living human embryos, is the laboratory of Professor Mio and his collaborators (see cover for this month). Among their accomplishments has been the implementation of high resolution microscopy capable of revealing dynamics of cell motility in human embryos [5], and the identification of a novel mechanism operative during the block to polyspermy [6]. Supplementing this technology with spinning disk imaging of fluorescent reporters of chromosomes and spindle components, and differential labeling of maternal and paternal genomes, the present study aimed at evaluating the fate of single pronuclear stage embryos, and in the process uncovered much more. Could it be that, as in the mouse, parental genomes exhibit some degree of autonomy relative to each other?

Their findings are to be interpreted with caution given the source of embryos, the manipulations required to both express and track biomarkers, and the limited number of samples being investigated. However, if repeated and confirmed, these results extend an ongoing conversation suggesting that zygotes of several mammals, including the human, engage in processes that delimit the final integration of maternal and 
paternal genomes to some as yet undetermined stage within or beyond the initial cell cycles [7].

That the first mitotic spindle seems somehow to be the locus of atypical behaviors contributing to the general problem of genomic stability in human embryos comes as no surprise, given the human embryos' reckless deployment of asynchronous cell cycle and cytoskeleton dynamics that would never be expected from well-behaved somatic cells. Moreover, has anyone noticed, other than genetics aficionados, the reports of tripolar spindles all the way from human oocytes [8] to embryos [9, 10]?

Products of tripolar mitoses underlie many of the arrested embryo phenotypes, reported for years now in the human ART experience [9]. And what underscores our ability to understand this and other imperfections may find promise in the application of methods that inform us of subcellular behaviors that we have yet come to fully appreciate. It is in this light that in closing that we draw attention to the most recent work coming from the EMBO laboratories of Jan Ellenberg in Heidelberg for both the technological bravado and surprising findings in the mouse zygote regarding separation of maternal and paternal genomes. In essence, what they have now accomplished using light sheet microscopy is to reveal the gender-specific generation of spindles for mom and dad that ultimately converge into one before effecting anaphase on the way to the two-cell stage. Unlike the work of Mayer et al. cited above, their results detected genome integration in two-cell embryos [11].

Collectively, these observations are causing much headscratching as we await the results of similar studies on the human conceptus. We have reached a point where foundational concepts such as syngamy may have to be re-visited, not only to deepen our understanding of early human development but also provide a science-based infrastructure upon which societal and ethical guidelines will be formulated based on solid observation and not historical bias.

\section{References}

1. Wilson EB. The cell in development and heredity: Macmillan, New York; 1925.

2. Fishman EL, Jo K, Nguyen QPH, Kong D, Royfman R, Cekic AR, et al. A novel atypical sperm centriole is functional during human fertilization. Nat Commun. 2018;9(1):2210.

3. Mayer W, Fundele R, Haaf T. Spatial separation of parental genomes during mouse interspecific (Mus musculus x M. spretus) spermiogenesis. Chromosom Res. 2000;8(6):555-8.

4. Mayer W, Smith A, Fundele R, Haaf T. Spatial separation of parental genomes in preimplantation mouse embryos. J Cell Biol. 2000;148(4):629-34.

5. Iwata K, Mio Y. Observation of human embryonic behavior in vitro by high-resolution time-lapse cinematography. Reprod Med Biol. 2016;15(3):145-54.

6. Mio Y, Iwata K, Yumoto K, Kai Y, Sargant HC, Mizoguchi C, et al. Possible mechanism of polyspermy block in human oocytes observed by time-lapse cinematography. J Assist Reprod Genet. 2012;29(9):951-6.

7. Destouni A, Vermeesch JR. How can zygotes segregate entire parental genomes into distinct blastomeres? The zygote metaphase revisited. Bioessays. 2017;39(4).

8. Haverfield J, Dean NL, Noel D, Remillard-Labrosse G, Paradis V, Kadoch IJ, et al. Tri-directional anaphases as a novel chromosome segregation defect in human oocytes. Hum Reprod. 2017;32(6): 1293-303.

9. Ottolini CS, Kitchen J, Xanthopoulou L, Gordon T, Summers MC, Handyside AH. Tripolar mitosis and partitioning of the genome arrests human preimplantation development in vitro. Sci Rep. 2017;7(1):9744.

10. McCoy RC, Newnham LJ, Ottolini CS, Hoffmann ER, Chatzimeletiou K, Cornejo OE, et al. Tripolar chromosome segregation drives the association between maternal genotype at variants spanning PLK4 and aneuploidy in human preimplantation embryos. Hum Mol Genet. 2018;27(14):2573-85.

11. Reichmann J, Nijmeijer B, Hossain MJ, Eguren M, Schneider I, Politi AZ, et al. Dual-spindle formation in zygotes keeps parental genomes apart in early mammalian embryos. Science. 2018;361(6398):189-93. 